\title{
COVID-19-INDUCED CHANGES IN OUTDOOR RECREATION HABITS IN LATVIA DURING WINTER HOLIDAY SEASON OF 2020/2021
}

Edgars JŪRMALIS, Latvian State Forest Research Institute Silava, Rigas Str. 111, Salaspils, LV-2169, edgars.jurmalis@ silava.lv (corresponding author)

Arta BĀRDULE, Latvian State Forest Research Institute Silava, Rigas Str. 111, Salaspils, LV-2169, arta.bardule@ silava.lv

Zane LİBIETE, Latvian State Forest Research Institute Silava, Rigas Str. 111, Salaspils, LV-2169, zane.libiete@ silava.1v

\begin{abstract}
In Latvia, with $53 \%$ of forest cover, many forest areas are favoured destinations for outdoor recreation in every season. Winter holiday season of 2020/2021 in Latvia coincided with strict lockdowns when normal everyday routines of most people were significantly disrupted due to COVID-19 pandemic, that likely changed outdoor recreation habits of people in scale, frequency and temporal distribution. Therefore, in the beginning of 2021, based on a representative sample of inhabitants of Latvia, we conducted a survey with questions pertaining to winter outdoor forest-related activities in general, as well as several traditional and popular activities that people often conduct specifically in Christmas and New Year holiday season, like collecting of Christmas trees in the forest, feeding wild animals, collecting materials for house decorations. These activities are often pursued together with friends and family, thus providing also socialization opportunities, an important aspect during lockdowns. The paper presents results concerning the frequency of forest visits, compared to preCOVID-19 situation, the types of recreational areas favoured, as well as the observed changes in these areas.
\end{abstract}

Keywords: outdoor recreation, forest, winter, Christmas holiday season, COVID-19

\section{INTRODUCTION}

Outdoor recreation is crucial for physical and mental health of people, especially considering the increasing urbanization and ever more widely recognized benefits of active lifestyle. In densely forested Northern Europe, forest ecosystems specifically play an important role in providing recreation opportunities, thus substantially contributing to human welfare (Tyrväinen et al., 2001; Gundersen, Frivold, 2008). During the recent decades, forest management in the region has evolved in the direction of providing more diverse ecosystem services, including recreational benefits. The current global challenges and commitments made by European countries (Green Deal 2019; EU Forest Strategy for 2030) are expected to further advance multipurpose forestry.

According to population surveys carried out in Latvia in 2018 and 2019, most respondents visit outdoor nature areas for recreation once or twice a week, and 16-49\% of the respondents consider outdoor forest areas (OFAs) important, especially if located close to waterbodies (Donis, 2020). OFAs are a popular recreational destination also in winter - 35\% of the respondents visited OFAs in workdays, but $48 \%$ of the respondents - during weekends or holidays (Donis, 2019).

Winter-specific traditional activities often include gathering materials from the forest for home decoration. The most popular Christmas and New Year decorations are Christmas trees (both natural and artificial), placed indoors or outdoors during the holiday season. In northern Europe, natural trees are popular, and in some countries, parallel to Christmas tree farms, trees may also be collected in the forest. Also in Latvia, the state forest management company "Latvia's State Forests" allows legal collection of natural Christmas trees (Norway spruce; Picea abies L. Karst.) - one per person. Naturally regenerated spruces can be collected in state forests from the vicinity of roads and ditches, under the canopy of mature forest stands and only outside areas under any protection regime. These Christmas trees cannot be higher than $3 \mathrm{~m}$, and exceed $12 \mathrm{~cm}$ stump diameter (Latvia's State Forests, 2015).

Collecting of other forest materials for home decoration is popular as well. These materials usually include boughs of evergreens, pine- and spruce-cones, lichen, decorative branches etc. Many families make their own Advent wreaths, and many people make them also for sale. Other traditions during winter time festivities include bringing treats to wild forest animals (deer, wild boars, elks and others) - food is placed on forest animal migration routes, preferably further away from public roads and housing. Usually, potatoes, carrots, apples, cabbages and grains are used for this purpose. This activity is not to be confused with methods used by hunters for the purposes of attracting and herding wild animals.

During the autumn period of 2020, Latvia observed a rise in cumulative COVID-19 infection rates, reaching a peak of approx. 690 cases per 14 days/100,000 people during the first weeks of January, 2021. On December $27^{\text {th }}, 2020$, 44 deaths were registered due to COVID-19 (COVID-19 statistika Latvijā, 2020). State of emergency was declared in the

Copyright (C) 2021 The Authors. Published by Vytautas Magnus University. This is an open-access article distributed under the terms of the Creative Commons Attribution License (CC BY 4.0), which permits unrestricted use, distribution, and reproduction in any medium, provided the original author and source are credited. 
country in November 2020. It was prolonged several times and finally lifted only in April. Thus, strict restrictions were in force during December 2020 and January 2021. As such, several lockdown and strict public safety measures were implemented, for example, neither public, nor private Christmas and New Year's celebrations were allowed (except within the circle of one's household), and several weekends were designated with evening/night curfews. Education in schools after grade 4 was organized remotely, and in-person interest-related education, as well as sport workouts could happen only individually. These impacts can be acquitted as meaningful on the basis for investigating any changes in behaviours and traditions. These restrictions also significantly limited socialization opportunities for all age groups, and this aspect, along with general insecurity due to unfamiliar and potentially dangerous situation and disrupted daily routines has caused such problems as increased stress levels, anxiety and depression (Fiorillo et al., 2020; Ahrens et al., 2021; Clemens et al.; 2020). During the pandemic, outdoor spaces have provided a significant relief to people under stress (Grima et al., 2020; Lenaerts et al., 2021). Both public and private outdoor spaces have been reported as important (e.g., Lehberger et al. 2021), and several papers reveal a significant increase in forest visits both in Europe (Derks et al., 2020; Pichlerová et al., 2021) and overseas (Foley, 2020; Stanturf, Mansuy, 2021). Moreover, the significance of outdoor areas has changed, as forests have acquired a new role not only as "green spaces" but also as "social spaces" where to alleviate the effects of social distancing and to connect with other people (Weinbrenner et al., 2021).

Our study sought to investigate the pattern of the use of outdoor forest areas (OFAs) for recreation during the winter holiday season 2020/2021 in comparison to the previous holiday season, and to find out whether any changes in some traditional activities carried out around Christmas and New Year had taken place. We hypothesised that 1) forest areas both with and without recreational amenities were important for outdoor recreation during the strict COVID-19 induced lockdown in winter holiday season 2020/2021, and 2) both frequency of visits to OFAs and involvement in outdoor activities traditional for the holiday season differed between respondents of different age groups and places of residence.

\section{METHODS}

Between 26 January and 28 January, 2021, an online survey was conducted in Latvia covering 1000 respondents (1000 valid responses). Survey questions were developed by researchers of Latvian State Forest Research Institute "Silava". Service of professional survey company (KANTAR, Ltd. TNS Latvia) was used to distribute the survey and to obtain representative data set. The survey was completely anonymous, administered in Latvian and Russian languages and covered respondents aged from 18 to 74 years. The survey questions had three blocks. The first one inquired about the respondents' habits in visiting OFAs with and without specific recreational amenities (including frequency, also compared to previous holiday season, as well as company for visits, e.g., individual visits, family, friends and/or colleagues). The second block of questions pertained to specific forest-related winter activities, usually carried out during Christas and New Year holiday season, namely, collecting Christmas tree in the state forest, gathering forest materials for decorating house and bringing treats to forest animals. Similarly, to first block of questions, these, too, included specifications about the frequency and company of visits. The third block of questions was related to the changes the visitors had observed in the OFAs during their visits. In case changes had been observed, the respondents were asked to shortly characterize them. All blocks of questions referred to the winter holiday season of 2020/2021 (December 2020/January 2021), to include also the time of Advent and holidays celebrated both by Latvian- and Russian-speaking population. In total, the survey consisted of 17 multiple-choice questions, one open-ended question and several questions about socio-demographic factors (age, gender, nationality, colloquial language in the family, location (rural or urban area), education level, employment status during the pandemic and others). While we inquired about forest visits in general, in the more detailed part of this study we intentionally excluded questions on winter sports (skiing, skating etc.). Instead, we focused on those outdoor recreational activities that have traditional significance, related specifically to the holiday season.

The sample included 516 female and 484 male respondents. We received a proportional number of responses (19$20 \%$ ) from all age groups, except for the age groups 65-74 and 18-24 years, for which we received slightly fewer answers (14\% and 9\% from all responses, respectively). Of our respondents $34 \%$ lived in Rīga, 25\% - in other cities and $31 \%-$ in rural areas of the country. Generally, our sample was representative to Latvia's population according to the data of Central Statistical Bureau of Latvia. In terms of employment, $6 \%$ of the respondents were unemployed, $8 \%-$ selfemployed, $5 \%$ were secondary school or high school students. $16 \%$ of the respondents were retired, and for $5 \%$ the employment status was that of stay-at-home partner. During the time period that was asked about, $8 \%$ of all respondents had been idle (at work standstill) due to COVID-19 pandemic restrictions.

The collected survey data were analysed with descriptive statistics. Responses were compared across response variants and demographic categories. To be treated likewise, the responses of the open-ended question prior to analysis were coded into five groups depending on the nature of the changes observed and the expressed attitude of the respondent towards these changes. The groups were: positive, neutral/positive, neutral, neutral/negative and negative. For example, a comment "forests are felled too much!" was marked as negative, while "there is a lot of forest felling" - as neutral/negative. Still, admittedly, coding was somewhat subjective and may, therefore, not entirely correspond to the intentioned replies of respondents. Figures were prepared using R package "ggplot2". 


\section{RESULTS AND DISCUSSION}

\section{Visits to outdoor forest areas}

Of all 1000 respondents, more than one half had visited outdoor forest areas (OFAs) either with or without recreational infrastructure for recreational purposes during December 2020/January 2021. Areas without specific recreational amenities seemed to be slightly more popular - they were visited by $44 \%$ of the respondents as compared to the areas with specific recreational amenities which were visited by $40 \%$ of the respondents. Repeated visits were more common than single visits ( $24 \%$ vs $16 \%$ and $29 \%$ vs $15 \%$ in case of forest areas with and without specific amenities, respectively).

The results revealed that approximately one third of respondents in 2020/2021 holiday season had visited OFAs more frequently than on the previous winter holiday season, and the more frequent visits were slightly more prevalent among the visitors of OFAs with specific recreational amenities (33\% and 28\%, respectively). The decrease of the frequency of visits was also more often reported by this group of visitors $-27 \%$ vs. $20 \%$ among those who favour areas without special amenities.

Forest visits were mostly carried out together with family members, somewhat more frequently when areas with amenities were visited (78\% and 66\%, respectively). Both in single visits and repeated visits the company of the family members was favoured. At the same time, in the case of repeated visits to OFAs without recreational amenities rather high percentage of respondents $-28 \%$ - had indicated individual visits. $35 \%$ of forest visitors indicated that there is at least one child in the family. Slightly more visitors to OFAs with recreational amenities had children if compared to visitors to areas without recreational infrastructure, namely, 38\% and $34 \%$.

The percentage of people visiting OFAs together with family was rather similar in the age group 18-44 years if places with specific recreational amenities were visited, and in the age group 25-44 years in case of visits to OFAs without recreational amenities. In the second case the share of positive responses dropped for the age group 45-54 years and rose again for the age group 55-64 years. Elderly people were also more likely to visit OFAs alone, and we assume that this may be related to more free time this age group has after retirement. Younger people were more likely to visit OFAs together with friends, and also the percentage of mixed responses was highest for the youngest age group in case of visiting OFAs without recreational infrastructure (Figure 1).
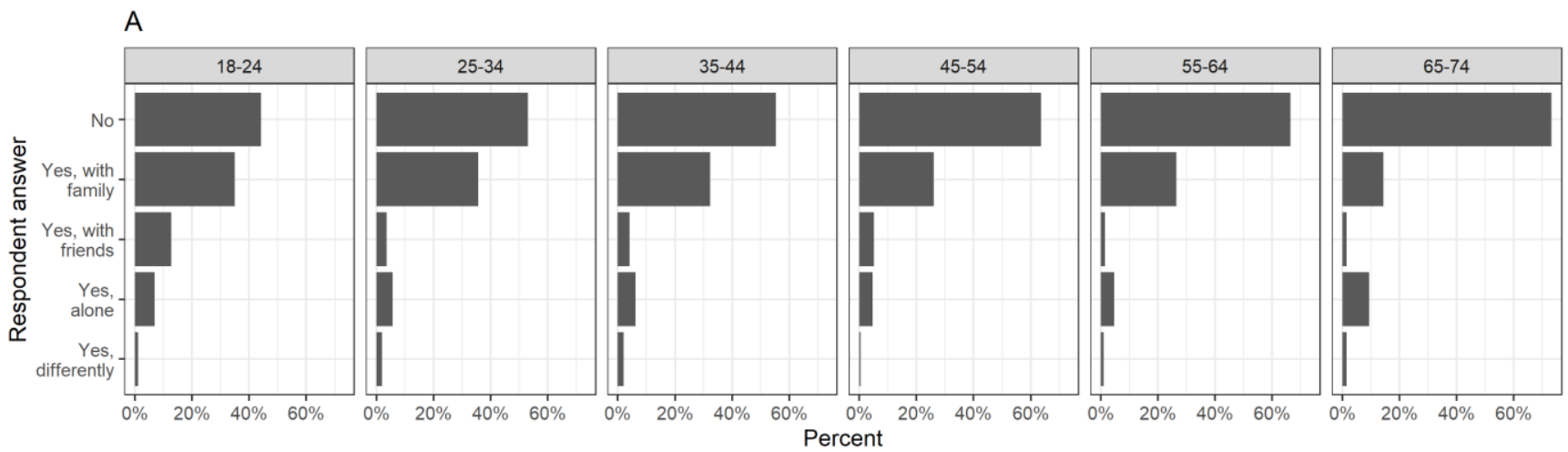

\section{B}
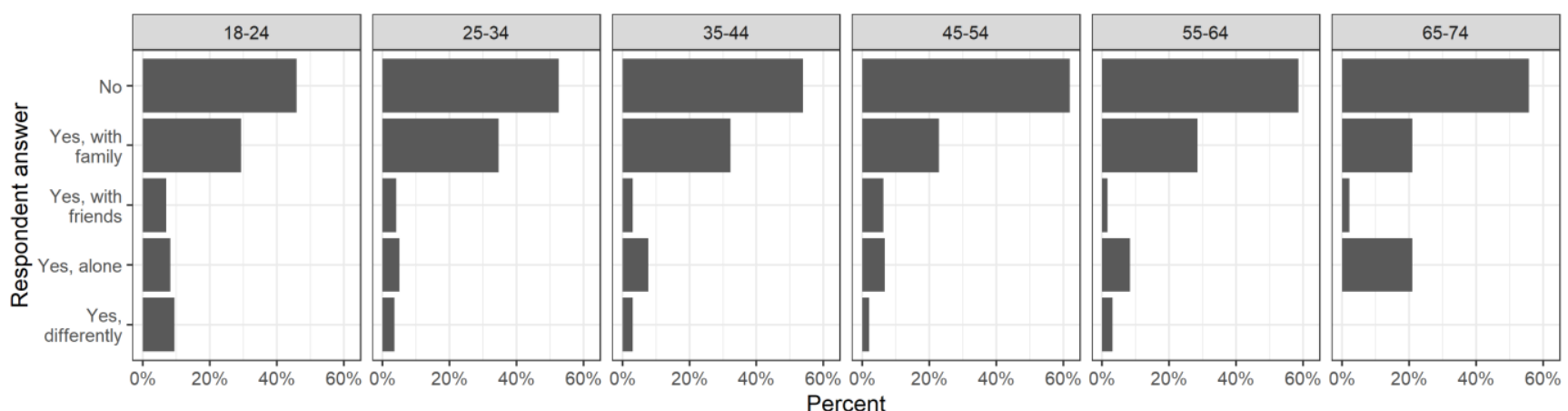

Figure 1. Visits to OFAs with (A) and without (B) recreational amenities by respondent age and mode of visit. "Yes, differently" indicates a mixed response, i.e., that forest visits sometimes are carried out together with family and sometimes with friends, or sometimes alone and sometimes with family.

Even though decidedly more than a half of the respondents worked at the time targeted by the survey, $7 \%$ indicated that their work during the holiday season had been at standstill due to COVID-19 restrictions. The percentage did not differ between the group of visitors preferring OFAs with special recreational amenities and without them. The share of respondents at work standstill during the time of interest was the same also within the group of those who did not visit OFAs. Thus, we cannot conclude that standstill has been a factor influencing the frequency of forest visits.

Our results provide a limited picture on patterns how COVID-19 has influenced the outdoor forest recreation. We did not ask specifically whether the frequency of forest visits of the respondent had increased due to COVID-19 situation, as we 
considered this to be a leading question, unfit to provide unbiased answers. The data, however, seem to provide some indirect proofs. The frequency of forest visits had increased more than decreased, if compared to the previous holiday season, and we believe that this change can, at least partly, be attributed to the COVID-19 situation. Also the fact that 15-20\% of the respondents who had visited the OFAs more frequently if compared to the previous holiday season, had conducted forest visits together with friends and colleagues (even though strict social distancing were in force at the time and meetings only within one household were permitted) indirectly points to the importance of OFAs as "social spaces", significant not only for healthy outdoor recreation but also for socializing, as indicated by Weinbrenner et al. (2021) and others.

\section{Traditional forest-related winter holiday season activities}

From the traditional winter holiday season activities, our respondents mostly engaged in the collecting of Christmas trees. Nearly one third of respondents, 30\%, confirmed they had done it in the holiday season 2020/2021, and more than $80 \%$ of them indicated that they have done that previously as well. $6 \%$ answered that they had not collected the Christmas tree on the previous holiday season but have done it on this one. Of the respondents who had collected Christmas trees, $47 \%$ were women and $53 \%$ - men. This was an activity that $62 \%$ of the respondents pursued together with their family. Interestingly, however, that when the share of men and women who had collected Christmas tree alone were compared, 39\% of those were women. The results indicate that this activity is less gendered than probably might be expected in Latvian conditions, however these aspects are not further explored in this paper.

Mostly people from rural areas collected Christmas trees, and most of them did that together with family members, even though in this residence group also the share of respondents who pursued this activity alone was rather high. For inhabitants of Rīga and other cities Christmas tree collection clearly was predominantly a family activity. Collection of Christmas trees was most popular among the age group 18-34 years, and for these respondents it was explicitly a family activity. Starting from age of 35 years, the share of respondents collecting the Christmas tree alone started to rise, and in the age group 65-74 years the share of people collecting Christmas trees alone was almost twice as high as share of people pursuing this activity together with family (Figure 2). It is important to note that our results did not filter the collection of Christmas trees for the purposes of selling.
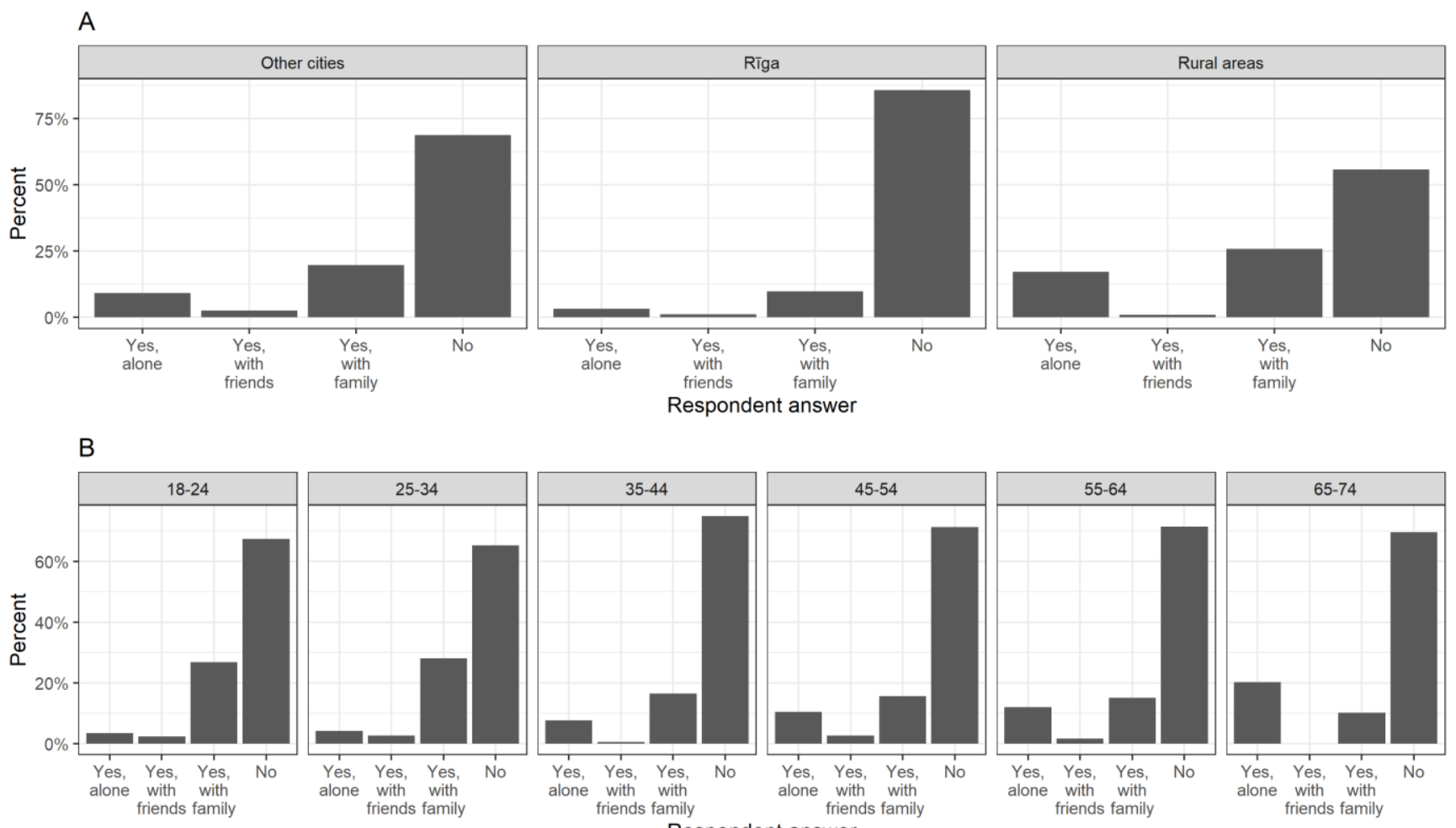

Figure 2. Collection of Christmas trees by respondent's type of residence (A) and age group (B)

$17 \%$ of the respondents replied affirmatively when asked whether they had in the forest gathered materials for home decoration in the 2020/2021 holiday season. This activity was mostly pursued together with family, as indicated by $66 \%$ of the respondents. $66 \%$ of the respondents also indicated that they had engaged in this activity also in the previous holiday season. Of the respondents who gathered decorative materials alone, $73 \%$ were women. Most respondents who gathered decorative materials lived in rural areas (44\%), however, if the positive responses from the inhabitants of Riga and other large cities were combined, they constituted a very similar share $-43 \%$.

$13 \%$ of all respondents indicated that they had visited forest to bring there some treats for the wild animals, and $65 \%$ had done that in the company of their family. For 53\% of them, the frequency of this activity had not changed, if compared with previous year, but $21 \%$ of them indicated that they had not done it in 2019/2020 holiday season. Somewhat unexpectedly, only $36 \%$ of the respondents who indicated this activity had children. It is possible, however, that 
affirmative answers were given also in cases of hunters bringing to the forest additional fodder for game during the winter time, but this is merely an assumption, as our data do not allow for more detailed analysis. Most respondents who brought treats to the forest animals lived in rural areas (45\%), but, similarly to the previously described activity, if responses from Rìga and large cities were combined, they together constituted almost the same percentage $-46 \%$.

\section{Changes observed in outdoor forest areas}

Of all respondents, $15 \%$ indicated that they had observed changes in the OFAs they had visited during 2020/2021 winter holiday season. Most of them (45\%) were inhabitants of rural areas. Comparatively high percentage of those who had observed changes lived in Rīga (25\%) and other large cities (18\%). The data from this sample, however, do not allow us to draw conclusions where these OFAs were located.

Of the 150 respondents who had observed the changes, $18 \%$ indicated that the changes were positive. Most often listed positive changes were related to the establishment and/or improvement of the recreational infrastructure, including information signs, as well as improved cleanliness of the OFAs. As indicated in other studies (e.g., Derks et al. 2020), with increased visitor flows, also recreational infrastructure gains increased importance, and forest managers will need to cope with this new challenge in the future.

Of all the observations, $37 \%$ could be classified as neutral, and most of those indicated increased number of visitors in the area. Some visitors had also noticed information signs concerning the social distancing, restricted access to the recreational infrastructure (e.g., closed observation towers). Other neutral comments included observations of seasonal changes in nature, as well as forest management activities.

Explicitly negative comments constituted $21 \%$ of all observations, and approximately half of them were related to forest felling, which is not surprising, considering that visible traces of forest management are usually valued negatively (e.g., Gundersen and Frivold 2008, Eriksson et al. 2012). Moreover, the survey questions pertained to the winter period when most of the forestry works are carried out. Observations of increased littering and unacceptable behaviour of forest visitors also formed rather significant part of the negative comments. This problem, too, has been identified in several previous studies, especially in relation to increased visitor flows due to pandemic (Derks et al., 2020, McGinlay et al., 2020). Several of the comments were rather general, for example, 'everything has become worse', but in two cases respondents provided a very detailed answer, listing all observed changes for the worst. The group of neutral/negative comments constituted $22 \%$ of all observations, and these were mostly related to forest felling.

The results about the nature of the observed changes, however, must be approached with caution, due to several reasons. Firstly, the coding into "attitude" groups was done subjectively - we did not explicitly ask whether the observed changes were perceived as positive or as negative. Secondly, population survey likely is not the best method for obtaining representative qualitative data; for this purpose, face-to-face interviews would be more suitable. Therefore, our data on the topic and especially their interpretation, may be considered rather as trends indicating the direction of future studies. Alternatively, as demonstrated in other studies, similar analysis of user content can be performed, on, for example, social media images. Thus, attitudes of forest area visitors can be "extracted" from various sources (Weinbrenner et al., 2021), improving the precision of categorizing opinions and emotional stances.

\section{CONCLUSIONS}

1. Outdoor recreation in forest was popular also in wintertime, and areas without specific recreational amenities seemed to be visited by slightly higher number of people. Outdoor forest areas were most often visited together with family, even though repeated individual visits to areas without recreational infrastructure were also quite common.

2. There is some evidence on the increased importance of visiting OFAs during the time of strict social distancing measures of COVID-19 pandemic. OFAs in this case serve not only as "green spaces" but also as "social spaces", providing opportunities to meet people and to socialize during lockdown.

3. Of the traditional forest-related outdoor activities pursued during the winter holiday season, collection of Christmas trees is the most popular one. It is more popular among inhabitants of rural areas and mostly done together with family members, even though this pattern changes with respondent age, and elderly people are more likely to collect Christmas trees alone.

4. Observed positive changes in the OFAs are related to improved recreational infrastructure and cleanliness. Neutral changes mostly refer to the increased number of visitors, but also informative signs about the social distancing is being noted, as well as restrictions to recreation infrastructure due to COVID-19. Negative comments are mostly related to forest felling and littering of OFAs.

Acknowledgement. The study was supported by the project " Forest management challenges under increased recreational pressure in the time of COVID-19 crisis " (No. lzp-2020/2-0167), financed by the Latvian Council of Science.

\section{REFERENCES}

1. Ahrens K. F., Neumann R. J., Kollmann B., Plichta M. M., Lieb K., Tüscher O., Reif A. 2021. Differential impact of COVIDrelated lockdown on mental health in Germany. World Psychiatry: Official Journal of the World Psychiatric Association, Vol. 20(1), pp. 140-141. https://doi.org/10.1002/wps.20830 
2. Clemens V., Deschamps P., Fegert J.M., Anagnostopoulos D., Bailey S., Doyle M., Eliez S., Hansen A.S., Hebebrand J., Hillegers M., Jacobs B., Karwautz A., Kiss E., Kotsis K., Kumperscak H.G., Pejovic-Milovancevic M., Råberg Christensen A.M., Raynaud J.-P., Westerinen H., Visnapuu-Bernadt P. 2020. Potential efects of "social" distancing measures and school lockdown on child and adolescent mental health. European Child \& Adolescent Psychiatry, Vol. 29, pp. 739-742 https://doi.org/10.1002/wps.20830

3. COVID-19 statistika Latvijā. 2020. Latvijas Atvērto datu portāls. Available at: https://data.gov.lv/dati/lv/dataset/covid19/resource/d499d2f0-b1ea-4ba2-9600-2c701b03bd4a/view/260bdcdb-f1ba-4a0b-85d5-e8834f1f516f

4. Derks J., Giessen L., Winkel G. 2020. COVID-19-induced visitor boom reveals the importance of forests as critical infrastructure. Forest Policy and Economics, Vol. 111, ID 102253. https://doi.org/10.1016/j.forpol.2020.102253

5. Donis J. 2019. Recreation preferences in different seasons. Report of the results of the research programme "The impact of forest management on forest and related ecosystem services", 225 p. [in Latvian]

6. Donis J. 2020. Recreation preferences and habits of non-wood forest product gathering of the inhabitants of Latvia. Report of the results of the research programme "The impact of forest management on forest and related ecosystem services", 249 p. [in Latvian]

7. Eriksson L., Nordlund A.M., Olsson O., Westin K. 2012. Recreation in different forest settings: a scene preference study. Forests, Vol. 3, pp. 923-943 https://doi.org/10.3390/f3040923

8. Fiorill, A., Sampogna G., Giallonardo V., Del Vecchio V., Luciano M., Albert U., Carmassi C., Carrà G., Cirulli F., Dell’Osso B., Nanni M.G., Pompili M., Sani G., Tortorella A., Volpe U. 2020. Effects of the lockdown on the mental health of the general population during the COVID-19 pandemic in Italy: Results from the COMET collaborative network. European Psychiatry, Vol. 63(1), e87, pp. 1-11. https://doi.org/10.1192/j.eurpsy.2020.89

9. Foley J.M. 2020. Outdoor Recreation, Greenspace, and COVID-19 in Maine. Capstone paper for Master of Policy, Planning, and Management, Program Muskie School of Public Service, University of Southern Maine, 29 p.

10. Grima N., Corcoran W., Hill-James C., Langton B., Sommer H., Fisher B. 2020. The importance of urban natural areas and urban ecosystem services during the COVID-19 pandemic. PLOS One, Vol. 15(12): e0243344, https://doi.org/10.1371/journal.pone.0243344

11. Gundersen V.S., Frivold L.H. 2008. Public preferences for forest structures: A review of quantitative surveys from Finland, Norway and Sweden. Urban Forestry \& Urban Greening, Vol. 7(4), pp. 241-258 https://doi.org/10.1016/j.ufug.2008.05.001

12. Katram savu svētku egli. 2021. Latvijas Valsts meži. Available at: https://www.lvm.lv/images/lvm/sabiedribai/kodrikstmeza/katramsavuegli1.pdf

13. Lehberger M., Kleih A.-K., Sparke K. 2021. Self-reported well-being and the importance of green spaces - A comparison of garden owners and non-garden owners in times of COVID-19. Landscape and Urban Planning, Vol. 212, ID 104108. https://doi.org/10.1016/j.landurbplan.2021.104108

14. Lenaerts A., Heyman S., De Decker A., Lauwers L., Sterckx A., Remmen R., Bastiaens H., Keune H. 2021. Vitamin Nature: How Coronavirus Disease 2019 Has Highlighted Factors Contributing to the Frequency of Nature Visits in Flanders, Belgium. Frontiers on Public Health, Vol. 9, 646568, https://doi.org/10.3389/fpubh.2021.646568

15. McGinlay J., Gkoumas V., Holtvoeth J., Fuertes R.F.A., Bazhenova E., Benzoni A., Botsch K., Martel C.C., Sánchez C.C., Cervera I., Chaminade G., Doerstel J., García C.J.F., Jones A., Lammertz M., Lotman K., Odar M., Pastor T., Ritchie C., Santi S., Smolej M., Rico F.S., Waterman H., Zwijacz-Kozica T., Kontoleon A., Dimitrakopoulos P.G., Jones N. 2020. The Impact of COVID-19 on the Management of European Protected Areas and Policy Implications. Forests, Vol. 11(11), ID1214. https://doi.org/10.3390/f11111214

16. New EU Forest Strategy for 2030. 2021. European Commission. 28 p. Available at: https://eurlex.europa.eu/resource.html?uri=cellar:0d918e07-e610-11eb-a1a5-01aa75ed71a1.0001.02/DOC_1\&format=PDF

17. Pichlerová M., Önkal D., Bartlett A., Výbošt’ok J., Pichler V. 2021. Variability in Forest Visit Numbers in Different Regions and Population Segments before and during the COVID-19 Pandemic. International Journal of Environmental Research and Public Health, Vol. 18(7), 3469 https://doi.org/10.3390/ijerph18073469

18. Stanturf J.A., Mansuy N. 2021. COVID-19 and Forests in Canada and the United States: Initial Assessment and Beyond. Frontiers in Forests and Global Change, Vol. 4, ID 666960 https://doi.org/10.3389/ffgc.2021.666960

19. The European Green Deal. 2019. European Commission. 24 p. Available at: https://eurlex.europa.eu/resource.html?uri=cellar:b828d165-1c22-11ea-8c1f-01aa75ed71a1.0002.02/DOC_1\&format=PDF

20. Tyrväinen L. 2001. Economic valuation of urban forest benefits in Finland. Journal of Environmental Management, Vol. 6 (1), pp. 75-92. https://doi.org/10.1006/jema.2001.0421

21. Weinbrenner H., Breithut J., Hebermehl W., Kaufmann A., Klinger T., Palm T., Wirth,K. 2021. "The Forest Has Become Our New Living Room" - The Critical Importance of Urban Forests During the COVID-19 Pandemic. Frontiers in Forests and Global Change, Vol. 4, ID 672909 . https://doi.org/10.3389/ffgc.2021.672909 